necessary, and hence was not done. The exact nature and extent of the operation may possibly be some day recorded by Mr. Horsley himself. All that I am concerned about here is its splendid practical results. From the day of its performance (more than two months ago) to the present moment all fever has ceased. As soon as the necessary period of rest had passed and food could be taken the body weight increased for some weeks at the rate of half a pound a day, and the patient is now as well as he has ever been in his life, and for a considerable time has been able to resume without fatigue the duties of an arduous practice. The congratulations which for the third time I ventured to offer immediately after the operation have happily been justified by the result, and the whole case presents, I think, one of the most striking examples of a supposed inexplicable fever, proving to be both explicable and removable when a source of local septic infection was once got at and removed.

The last case that I shall bring to your notice differs from those previously narrated in the fact of its having arisen in the course of a surgical affection. On Feb. 15th, 1895, I was requested to see with my friend and colleague, Mr. Robert Jones, and Dr. Chisholm of Woolton, a man aged twenty-three years, a resident of that place. This patient had always been perfectly healthy up to about a year previously, when he met with a very severe accident, which, besides bruising him generally, caused compound fracture of the bones of the right leg. As the result of this he became subject to great, and what was feared would prove a permanent, deformity, a circumstance of such serious importance to a young man that the advice of Mr. Jones was sought as to whether anything could be done to remedy it. By a series of ingeniously devised and successfully executed operations this deformity was entirely overcome, and all that remained was a very extensive area denuded of skin, which it was proposed to fill up by grafting. For this purpose plastic operation was carried out on Feb. 3rd to supply the place of the destroyed skin. Everything that prudence could suggest seemed to have been devised to ensure the success of this. A room was specially selected on account of its cheerful aspect and freedom from every suspicion of sanitary defect. Two nurses of skill and experience in antiseptic surgery were engaged. For a day or two everything went well. The wound was from the first antisepticised. No hand was allowed to touch it except after thorough cleansing with disinfectant. The bowels were carefully attended to, and every hope entertained of success, when a slight feeling of malaise on the evening of the 3rd, accompanied by a moderate rise of temperature, began to excite uneasiness. The wound was examined and found to be sweet. Day by day, however, the symptoms were intensified. The temperature rose as high as $104 \cdot 4^{\circ} \mathrm{F}$., the rise being preceded by a feeling of shivering and occasionally by a somewhat severe rigor, and followed by profuse sweating. Emaciation set in and was progressing somewhat rapidly, in spite of a fair amount of judiciously selected nourishment, and the utmost anxiety was felt and expressed on all hands for his condition. Ten days after the commencement of these symptoms, which continued daily and increased rather than diminished in intensity as time went on, I was asked to see hrm. A very careful examination of all the large organs failed to detect anything that could throw light upon the condition. The heart, lungs, kidneys, and other abdominal organs seemed to be healthy. I examined the nose and could find no evidence of disease in it that might explain the symptoms. I then asked permission to examine the granulating surface. It was carefully exposed by removal of the antiseptic dressings and certainly at first sight looked very healthy. After a thorough cleansing of my hands in a weak solution of perchloride of mercury I went round its edge. On almost every portion of this there was the white film creeping in by which the gap was being filled in, and the skin to a gentle touch seemed firm and adherent. From one minute spot, however, the white film was absent, and here the skin, instead of adhering to the subjacent tissues, felt slightly loose. On pressing over this minute bit of skin a single drop of pus was squeezed out.

cleansed probe introduced at the spot penetrated for a few lines. I ventured to express the belief that absorption of septic material through this very small spot, that seemed to have escaped the reach of the antiseptics, was sufficient to account for all the symptoms, and with the view of putting this to the test we agreed to instruct the nurses to inject a weak solution of perchloride of mercury by means of a small syringe, whose fine nozzle was to be introduced under the skin at the point where it had admitted the probe, but to make no other alteration in treatment, which had consisted mainly of the administration of quinine. The moment this was done the temperature fell to normal and never again rose. The patient has for some time been at the seaside convalescent.

\section{THE OPERATION FOI THE RADICAL CURE OF HYDROCELE BY EXCISION OF THE SAC, ILLUSTRATED BY A SERIES OF CASES. ${ }^{1}$}

BY C. B. LOCKWOOD, F.R.C.S. Eng. ASSISTANT SURGEON TO ST. BARTHOLOMEW'S HOSPITAL; SURGEON TO THE GREAT NORTHERN CENTRAL HOSPITAL.

I VENTURR to introduce this subject because it has not yet been discussed by the Medical Society of London, also because the operation for the cure of hydrocele by excision of the sac does not seem to be so well known as it un. doubtedly deserves to be. During the last ten years (1885 to 1894 inclusive) one hundred and thirteen cases of hydrocele were treated by operation in the wards of St. Bartholomew's Hospital. ${ }^{2}$ only thirteen of these are said to have been treated by incision and excision of the sac wall. Forty-eight of the remainder were injected with iodine; forty-five are said to have had radical cure done; and, lastly, seven were treated with setons. With the help of Mr. E. G. B. Adams, to whom I am under a great obligation, I have examined the notes of these cases. There is no doubt but that the forty-five who are said to have been treated by "radical cure" had the hydrocele injected with iodine, black wash, or carbolic acid, the last two being used in a very few instances. Hydrocele is such a common disease and causes so much mental and physical inconrenience that some good reason must exist to explain why only 110 cases passed through the wards of a great hospital in a decade. I myself am inclined to attribute it in a measure to the uncertainty of injection, and to the fact that besides being uncertain it is very painful. My own observations have long caused me to look askance at this procedure. That it of ten failed there could be no doubt, but I did not know in what proportion; that it was exceedingly painful was also evident; and that epididymitis and orchitis were not infrequent consequences could not be denied. Now, whatever the patients themselves might think, it seems evident that one would be chary in recommending an operation which, after much pain and discomfort, might not succeed, or which might leave the patient with an additional discase. With regard to the question of failure I was not astonished to read in Mr. Jacobson's recent work that he estimates the failures after injection at from 8 to 10 per cent. ${ }^{3}$ The exhaustive labours of this writer and his temperate and judicial attitude give great weight to this statement.

With the help of Mr. Adams I have examined the notes of the cases of hydrocele in the wards of St. Bartholomew's Hospital during the last ten years. We have abstracted the notes of seventy-four patients who had been treated by injection, the total number of injections being ninety-three. In six of these the ultimate result was doubtful; they were not cured when last seen. ${ }^{*}$ In twenty-four the injection had undoubtedly failed. The above seems a very high proportion of failures. It is to be remembered, however, that many of the cases may have been admitted into the hospital because they were known to be intractable. Nevertheless, they deepen my own distrust of the so-called cure by injection. The history of these twenty-four failures is remarkable: ten failed after one injection, eleven had two injections, one had three injections, and two had four. In those which had two, three, or four injections the result is in many cases unknown, but some were ultimately treated by excision of the sac. Of the two cases which were tapped four times, one, a

1 Read before the Medical Society of London on Oct. 14th, 1895. 2 St. Bartholomew's Hospital Reports, Statistical Tables, prepared by the Surgical Registrar. Three cases treated by seton are accidentally mitted in the year 1889

3 The Diseases of the Male Organs of Generation, p. 141. London, 893.

* One bas since written to say he considers himself well, the swelling having "gone right down." I am greatly obliged to Mr. Maxwell for much help in obtaining the addresses of these cases. 
medical man, tells me that he now, after much suffering, has a spermatocele; the other seems to have been cured by carbolic acid after three injections with iodine. The patient who was injected three times had a most remarkable career. His hydrocele, which is said to have followed a blow, was tapped, thrice injected with iodine, twice incised and drained, and, finally, laid open, painted with liquor iodi, and packed with iodoform gauze. There is reason to believe that this was successful. The case was described by Mr. Willett in the discussion before the Royal Medical and Chirurgical Society. ${ }^{5}$ It may be noticed that excision of the parietal layer of the tunica vaginalis was not performed.

Out of the twenty-four operations which I have now done for the cure of passive hydrocele, two had previously been injected with iodine and relapsed. When the tunica vaginalis was opened no adhesions were found, but in one the testicle was chronically inflamed, although the injection had been done eighteen months before the operation, and the other has still a nodular condition of the testis and epididymis. These two cases of relapse are included in the twenty-four which have just been mentioned. Thus the chances of relapse after an attempt at cure by injection are very considerable; rather over 32 per cent. according to the statistics of St. Bartholomew's Hospital. Evidently the operation is not one to be recommended with confidence. With regard to the painfulness of it, I feel sure (in spite of the enthusiastic statements of some surgeons) that it is considerable. Putting aside what I myself have seen, it is clear from the notes that, although cocaine was freely used, pain which needed morphia for its alleviation was quite common and occasionally was so severe as to make the patient sick. It seems unreasonable to suppose that a violent irritant can be applied to the surface of a sensitive organ like the testicle without causing consiclerable pain. Two of the patients upon whom I operated for radical cure of lyydrocele by excision of the sac had, as I have just said, previously been operated upon by the injection of iodine. They were most emphatic that the excision was much less painful, and was, indeed, comparatively comfortable compared with injection. Nor am I convinced that injection with carbolic acid has the advantages which some have claimed for it. I can only find that five patients were injected with carbolic acid in the wards of St. Bartholomew's Hospital in the ten years 1885 to 1894 inclusive. They receired six injections. Two of these injections failed. In one case a second injection with carbolic acid seems to bave succeeded, but it is said that the epididymis was much enlarged. In a second case an unsuccessful injection with carbolic acid was followed by an unsuccessful injection with iodine. Finally, the parietal layer of the tunica vaginalis was excised. The other three patients were probably cured by one injection with carbolic acid. One is said to have suffered pain. This might be expected. Experiments upon animals incline me to think that carbolic acid is a violent remedy, and no one can deny that the testicle is a sensitive organ.

I do not propose to discuss all the alternatives to injection. A case has been mentioned in which incision and drainage failed twice. A diverticulum of the tunica vaginalis may, it is said, have been the cause of these persistent failures. Setons were inserted seven times into the hydroceles of infants and young boys. One of these is known to have relapsed and had a seton inserted for the second time. Partial excision of the parietal layer of the tunica vaginalis has also been tried. In one of these it is said that "so much of the sac was removed that it was difficult to bring the remainder together." The wound was drained for fourteen days, but nevertheless, before the man left " a small fluid tumour had already returned." Incision of the tunica vaginalis and after-packing with lint and subsequent sepsis and suppuration is a repugnant procednre. Fixcision of the sac, on the other hand, may be rendered an aseptic process, and seems to me to afford an excellent prospect of success. It seems reasonable to suppose that the removal of about nine-tenths of the diseased secreting membrane, and the exposure of what is left to the loose cellular tissue of the scrotum, could hardly be followed by a reaccumulation of the bydrocele fluid. The results of the operation will, I think, go far to show that this assumption is correct. And here it is to be said that the title of this paper is not strictly applicable to the operation performed upon ordinary hydrocele of the tunica vaginalis. For the cure of these only the parietal layer of the tunica vaginalis has been excised
(Fig. 1), but in encysted hydrocele the whole sac is cut away. I have now excised the whole of the parietal layer of the tunica vaginalis twenty-five times. All of these were done for the cure of hydrocele, with the exception of one which was done for hæmatocele. No attempt whatever was made to select the cases. The youngest was sixteen years old, the oldest sixty-eight. Some could hardly be considered good subjects for an operation. A man aged forty-one had been a heary drinker. His face was covered with acne rosacea. He had a high-tension pulse and probably some aortic stenosis. His urine contained a trace of albumen. He took ether well and suffered no apparent harm from the operation. A man aged sixty-three who had acne admitted that he drank; another, who was a plumber, suffered from lead poisoning; several had chronic bronchitis. This is a very objectionable complication, on account of the anæsthetic. However, by choosing the warm months of the year for the operation and by skilful administration of the anæsthetic this complication need cause little anxiety. In several cases the hydrocele was accompanied by other affections. In one a hydrocele on the right side and a varicocele on the left were operated upon at the same time. In another both sides were operated upon at the same time, the hydrocele being double. In another case the presence of an acquired hernia upon the same side as the hydrocele made no difference. A man who had a hydrocele and organic strictures of the urethra was operated upon first for the cure of the hydrocele, and a week later for the cure of the strictures. The last operation was followed by orchitis. In one case the hydrocele was bilocular. The testicle was surrounded by an ordinary hydrocele of the tunica vaginalis. A second large sac, full of about half a pint of clear yellow fluid, lay above the head of the epididymis. Both sacs were treated in the usual manner, the upper one being entirely removed. The operation was performed for various reasons-in some because of the size and weight of the hydrocele; in others for pain and discomfort, especially whilst riding upon horseback. Some were done to enable the patients to enter the army or other public services. One was done to enable the patient to wear a truss for a hernia which was unsuitable for radical cure. Some were performed because the patients were weary of being tapped; one man had been tapped twentyfour times. One patient was alarmed because his hydrocele had been burst at football. This accident had not brought abont a cure, as happened to a man I saw under Mr. Butlin's care, and of whom it is stated that his hydrocele had been burst by the wheel of a wagon passing over it. Another reason might, I think, influence the decision. At various times I have dissected a number of hydroceles. In the large ones of long duration the testicle had become flattened out and wasted, and apparently spoilt. In some of the operative cases the gland was considerably altered, the epididymis having become separated from the body of the testis.

Before operating for the radical cure of hydrocele by excision of the sac it is, as a rule, advisable to tap once to ascertain the condition of the testis. It would be disappointing to find a gumma, or a mass of tubercle, or even a malignant growth. Inasmuch as the fluid in a hydrocele is quite thin, like water, a very small trochar and cannula suffice for the tapping. A cannula of $2 \mathrm{~mm}$. diameter is quite large enough. The instrument usually figured in textbooks is a relic of mediæral surgery. Strange to say, one of those upon whom I intended to operate underwent spontaneous cure. A man aged sixty-five came in January, 1894, with a hydrocele of two years' duration. It had been tapped five times. He had bronchitis, so I tapped it again and told him to come in June to be cured. He returned in June with no trace of hydrocele, and said that after the tapping it had rapidly refilled and then got quickly well. He remains quite well of his hydrccele at this date (October, 1895). He attributed his cure to some spirits of camphor which he was taking. I also find it stated in the notes that a youth aged seventeen, who was under the care of Mr. Thomas Smith, had undergone spontaneous cure of his hydrocele. He had had it three years, and it had been injected once with iodine, but had relapsed. No reason could be assigned for the cure. This event is, of course, too rare to have any practical bearing upon the question of operation.

The operation of excision of the parietal layer of the tunica vaginalis is exceedingly simple. An incision is made the whole length of the long axis of the hydrocele The sac is exposed and separated from the scrotum until 
the spernatic vessels are almost in view. It matters little if the testicle is entirely witholrawn from the scrotum. A puncture is made to let out the hydrocele fluid. 'Ihis small opening is enlarged to admit the finger to ascertain the position of the testicle, epididymis, and vas deferens. Occasionally the vas is upon the front of the sac, having been clisplaced. 'The testis, too, is sometimes in front, as in one of my cases. As a rule this point will have cleared up before the operation is begun; but when the sac is thick the shadow of the testis cannot be seen. The finger in the sac also makes out the exact limits of the epididymis and of the testicle. In bic old hydroceles these organs are flattened out and sometimes pulled apart. In one of the cases upon which I operated this had happened, and the epididymis, separated from the testis, lay almost in front of the sac.

These points having been cleared up the whole of the parietal layer of the tunica vaginalis is cut away to within a guarter of an inch of the testicle and epididymis, so that these organs are left in the condition shown in the accompanying sketch. (Fig. 1.) Much misconccption seems to

Fig. 1.

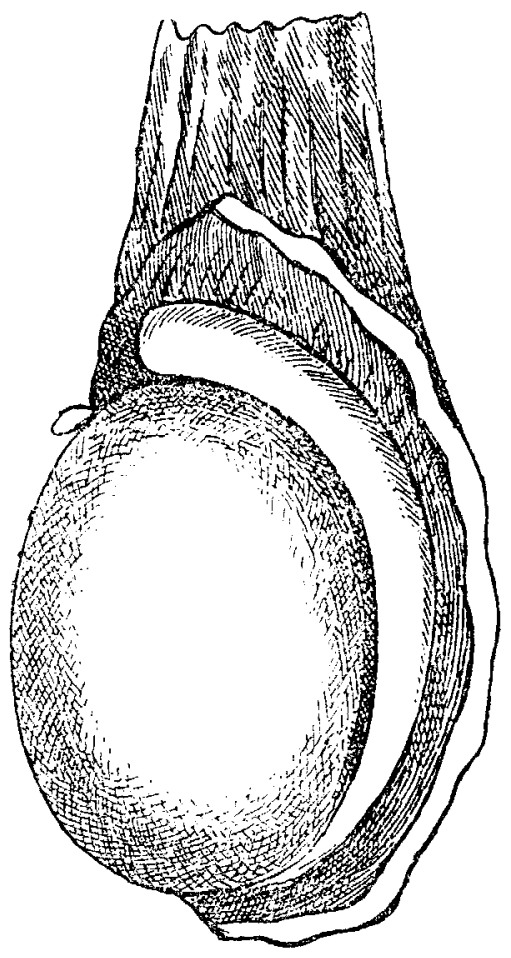

Showing how much of the tunica vaginalis is removed for the cure of hydrocele.

exist as to the quantity of tunica raginalis which is taken away. I am continually asked whether the visceral layer is dissected off the testis and epididymis. Sometimes in very big hydroceles the tunica vaginalis runs up the front of the spermatic cord. This prolongation must be thoroughly removed. The arrest of hæmormage is cf the utmost importance in this, as in other operations upon the scrotum. A hrmatoma easily forms in the scrotum and letracts considerably from the comfort of the patient and from the success of the operation. In one of my cases no vessel required ligature, but as a rule eight or twelve have to be secured with fine twisted silk. As a further provision against a hrematoma a large drainage-tube ( $\frac{1}{3}$ in. diameter) is laid along the depths of the wound and brought out at its upper angle. The rest of the skin incision is closed with fishing-gut sutures placed about a third of an inch apart. Trouble expended in obtaining accurate apposition of the wound is well repaid. 'The skin of the scrotum heals with great rapidity, and the union becomes guite strong in a week. It may be obscrved that no caustic is applied to the visceral layer of the tunica vaginalis, which is, of course, left behind. I do not think such applications are required, and they would increase the pain and also cause orchitis. As I have said, twenty-four hydroceles wore treated in this way. In acdition a hamatocele was met with, and received the same treatment. After all the blood and clot had been taken away the whole of the parictal layer of the tunica vaginalis was weised. 'The after-treatment was the same as that of the hyilincele cases, and will be described presently. Repair was rapid, and the after-result left nothing to be desired.
It would not, in $\mathrm{my}$ opinion, be justifiable to perform these operations for tho cure of hydrocele without stringent aseptic precantions. Inasmucl as surgeons differ as to what these shonld be perhaps I may be allowed to say very briefly what was done in all of these operations. The aseptic precautions pertain mainly to the preparation of the patient, of the surgeon and his assistant, and of the instruments and materials. The evening before the operation the patient is thoroughly shaved and has a hot bath with abundant soaping and scrubbing. The skin having been cleansed as far as can be done by soaping and scrubbing, it is further prepared for disinfection by extracting its fatty matter with ether or turpentine. It is disinfected by being washed for two minutes with a 1 in 500 solution of biniodide of mercury in rectified or methylated spirit. This is washed away with biniodide of mercury lotion ( 1 in 2000), and the skin is covered with a covering of carbolic gauze wet with the same lotion. It is, I think, advisable to add some glycerine to this lotion to help to keep the covering moist and assist the chemical to penetrate the skin. It is usual, also, to give a mild purge the night before the operation. These precautions are used for hospital patients; but for others less drastic measures usually suffice. The hands of the surgeon and of his assistants are apt to be a source of infection. After cutting the nails short, and scrubbing for three minntes with soap and hot water, we disinfect them by soaking for two minutes in the same solution of spirit and biniodide of mercury ( 1 in 500) as was used for the patient's skin. This has hardly any harmful effect even upon delicate skin. My hands are quite unable to bear the strong solutions of carbolic acid which some surgeons recommend. Very few instruments are required; a knife, a pair of scissors a needle, and a few pairs of pressure forceps are all that is necessary, These, together with the drainage-tube, are sterilised by boiling for a quarter of an hour. Fine twisted silk (No. 0 size) is used to ligature bleeding vessels, and fishing gut for closing the incision. These are also sterilised by boiling, and together with the instruments are afterwards kept in freshly made carbolic solution ( 1 in 40). After the patient has been anæesthetised the field of operation is prepared by removing the protective dressing and thoronghly wrapping up the penis in carbolic gauze which has been soaked in binionide of mercury lotion ( 1 in 2000). This "phallic shield" is of the greatest importance in this and other operations about the genital organs, especially in operations for varicocele and for the radical cure of hernia. The area of operation is surrounded with towels sterilised by boiling or steaming for half an hour, and kept wet with 1 in 40 carbolic lotion. One of these towels is passed across the thighs and under the hydrocele to support it. Before making the incision the skin receives a final swabbing with spirit and biniodide, and is then sluiced with 1 in 2000 biniodide of mercury lotion, which is used throughout the operation. I use sponges prepared by the sulphurous acid method.6 'lhe wound is dressed as follows: After a thorough dusting with iodoform crystals the scrotum is covered with a layer of 5 per cent. carbolic gauze soaked in biniodide of mercury lotion ( 1 in 2000). This is covered with alembroth wool and an outside dressing applied. The outside dressing is the usual eight-fold layer of carbolic gauze with a covering of jaconet. It is accurately cut to pattern and fitted with great care. (Fig. 2.) lt is triangular, with an aperture near the base for the penis to pass through. To the apex of the triangle two strong bands are fixed. When the dressing is in position these bands fix its apex against the perineum and are carried round the thighs to meet the pelvic band in front. This is a similar band of soft material which is fastened to the other angles of the dressing. They secure it firmly in position by being carried round the pelvis. The straps are best made of stout bandage or of webbing. After they have been pulled tight a little extra alembroth wool may be stuffed beneath the dressing to exclude air and make some pressure upon the scrotum. I have used this dressing now for a great number of cases of radical cure of hydrocele and varicocele, for castration, and other operations on the scrotum. I have no doubt but that other surgeons have bethought themselves of such a simple device. It is quite safe and very easy to adjust. The patients find it most comfortable, and are able to turn about in bed and if necessary get up with it on. It enables us to dispense with bandages, always

6 Report upon Aseptic and Septic Surgical Cases, with special reference to the Disinfection of Skin, Sponges, and Towels. C. B. Lockwood Brit. Med. Jour., Jan. 27th, 1894. 
dificult to apply in this region, and notoriously insecure. The after-treatment of these cases is simple and uniform. After the anrsthetic has passed off any light diet may be given, and the minor indulgences need not be stopped. The dressing is taken off at the end of forty-eight hours for the removal of the drainage-tube. This is done with the same precautions as those used for the operation. On the seventh or eighth day the dressing is finally removed and a suspensory bandage of linen applied. The patient now gets up to lie on a couch, and is able to begin work again within a fortnight.

The immediate results of excision of the parietal layer of the tunica vaginalis seem to leave little to be desired. The

Fia. 2.

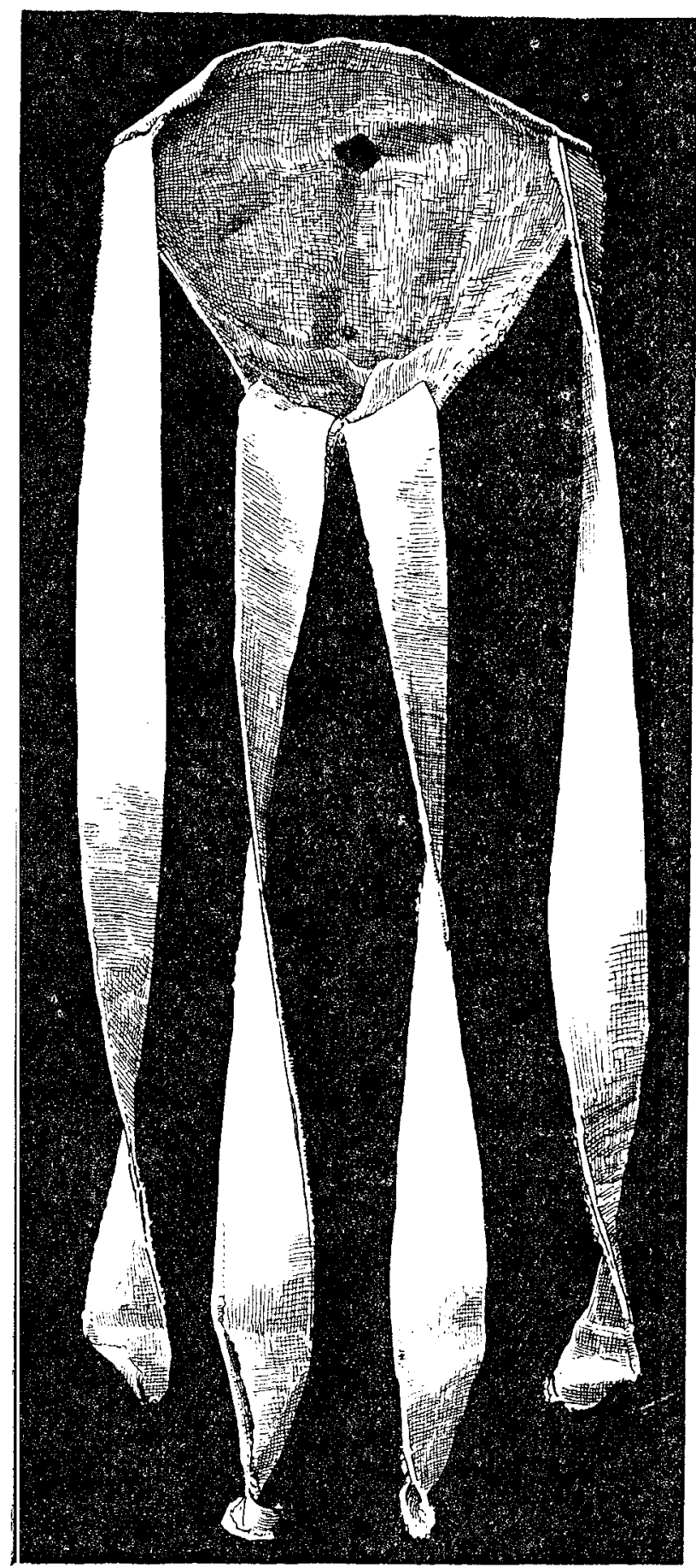

Ontside dressing used after operations upon the scrotum. From a photograph by Mr. Horder.

asepsis, which is so essential to safety, seems easy to secure. Only one of the cases had subacute suppuration, which was by no means severe. Owing to his physical conformation urine escaped several times into the dressing. We were aware of the likelihood of this accident and endearoured to shut off the wound with iodoform, collodion, and so forth. The man, however, was negligent and unintelligent, and did little to aid our efforts. Seven months after the operation he was quite cured, and, except for the scar, it would be impossible to find anything abnormal.

A striking feature of these cases has been the absence of orchitis. The case which has just been mentioned is supposed to have had some orchitis, and a youth was found to have some orchitis at the operation; but I am not aware that any of the others had it. Indeed, the testicle seems to bo surprisingly tolerant of any reasonable amount of handling. With the above exception the after-course of these twenty-five cases has been quite monotonous. The drainagetube was withdrawn in from forty to forty-eight hours, and the stitches removed six days later. By this time the wound was healed and merely required protecting with a little wool. After the removal of the stitches the patient was provided with a linen suspender, and got up to lie upon a couch. He was usually fit for work within a fortnight. The patients themselves greatly appreciate the relief which the operation affords, and have been profuse in their expressions of gratitude.

I think the foregoing shows that when excision of the parietal tunica vaginalis is done with strict aseptic precautions the immediate results of the operation leave little to be desired. The greatest pains have also been taken to ascertain the after-results. It may be noted that we have to deal with twenty-three patients upon whom excision of the parietal layer of the tunica vaginalis had been practised twenty-four times, the hydrocele having been on both sides in one instance.

Everyone will acknowledge the extreme difficulty of tracing cases in London. I have, howerer, succeeded in following up sixteen of these patients. Fourteen have been seen by myself or other surgeons, and are all cured, including the case of clouble hydrocele. Two have written to say they are cured. One of these patients has been well for close upon two years, two orer eighteen months, and none less than three months. To these may be added another case, that of a man upon whom my friend and colleague, Mr. Bowlby, performed exactly the same operation. It was done on Nor. 7th, 1894, and the patient is now quite well (Oct.4th, 1895) ${ }^{7}$ 'Thus I have not yet met with a relapse after complete aseptic excision of the parietal layer of the tunica vaginalis. I am fully aware that relapses have been described $;^{8}$ but it is probable that those cases were not operated upon in the same way as those dealt with in this colnmunication.

Examination of cases which have been operater upon shows that the scar of the incision is hardly visible. 'The testicle slips about quite freely within the scrotum. The gland in most cases is larger than its fellow, but quite soft and painless. I have observed this slight enlargement in cases which have been cured by iodine. It has probably nothing to do with the operation, but is related in some way to the hydrocele.

It is not intended upon this occasion to touch upon the pathology of hydroccle. Doubtless more than one cause has to be considered. Dr. Kanthack, pathologist to St. Bartholomew's Hospital, kindly examined the tunica vaginalis removed from two cases of passive hydrocele. $\mathrm{He}$ found in the thickened membrane evidence of chronic inflammation. At my suggestion tubercle bacilli were sought for, but none were found. The mammillæ scattered orer the thickened tunica vaginalis in cases of hydrocele are very suggestive of tubercle.

Inasmuch as they have the closest relationship to the cure of ordinary passive hydrocele, I propose to mention very briefly a case of operation for congenital hydrocele and another one in which there was hydrocele associated with hernia. The first was that of a youth who had a congenital hydrocele of the right side. The fluid in the sac could be reduced into the abdomen. An incision was made over the inguinal canal, and a long, narrow peritoneal tube was found leading into the general peritoneal cavity. This was separated from the spermatic cord and divided, and the stump fastened beneath the arching fibres of the internal oblique and transversalis. ${ }^{9}$ The inguinal canal did not require repairing, but the external abdominal ring was closed to its proper size with the usual silk sutures. No drain was inserted, and the wound healed by first intention. It will have been noticed that the tunica vaginalis was not touched, but was left alone, as in an ordinary case of congenital hernia. I now regret that I did not excise the parietal

7 The patient, together with fourteen others, was shown to the Medica Society at the meeting

$\gamma$ Some remarks on the Radical Cure of Hydrocele, with Notes of Two Cases of Excision of the Tunica Vaginalis, followed by Recurrence the Hydrocele. Henry Morris Transactions of the Royal Medical and the Hydrocele. Henry Morris, Transactions of the Royal Medical and March 3rd, 1888.

$\boldsymbol{g}$ The Rarlical Cure of Femoral and Inguinal Hernia. By C. B.

9 The Rarlical Cure of Femoral and
Luckwood. THE LaNCL, Nov. 25th, 1893 . 
layer, because five months after the operation there was some swelling about the testicle and perhaps a little fluid in the tunica vaginalis. The removal of the parietal layer of the tunica vaginalis in a case of this kind would be a very slight addition to the operation. In future I shall certainly take it away. Indeed, in another case of hydrocele which was associated with hernia this proceeding was adopted. The hydrocele seemed like one of the ordinary kind, but the cord was thickened, and it was thought that there was a narrow and patent processus vaginalis plugged with a strip of omentum. The operation which I usually perform for the radical cure of hernia was done. ${ }^{10}$ The peritoneal canal was occluded and the inguinal canal repaired. 'The lower part of the sac was laid open and in great part removed. It was difficult to make out its exact relation to the testicle, but it closely enveloped it and was, I thought, composed of the upper but not the lower part of the tunica vaginalis. This wound was not drained, and healed by first intention. Mr. Withers informs me that the hydrocele is cured. It is hardly necessary to point out that the above was a chronic hydrocele of a hernial sac. I have many times met with acute hydrocele in strangulated hernia, but in these it seems unnecessary to excise any of the tunica vaginalis. I have never known the effusion to return and persist after it has been evacuated.

Encysted hydroceles of the spermatic cord are also most suitable for excision of the sac. Apart from cases of hernia, I have not myself had an opportunity of dissecting out the sac of an encysted hydrocele of the cord. It is, however, a simple and safe procedure and much to be preferred to injections. From the nature of the case a relapse could not occur. Two patients who were operated upon by other surgeons write to say they are cured.

\section{A CASE OF EXTRA-UTERINE FEETATTON; OPERATION NEAR FULL TERM; CHILD LIVING; DEATH OF MOTHER THREE WEEKS AFTER DELIVERY.}

BY MONTAGU HANDFIELD-JONES, M.D. LOND.,

ABSTETRIC PFXSICIAN TO, ATD LECTURFR ON MIDWIFERY ANDO DISEASES OF WOMEN AT, ST. MARY'S HOSPIIAT.

THE patient was a woman aged twenty-six years, married seven years previously, and had one child (a boy). This confinement took place twelve months after marriage, was quite normal, and the child, who was healthy, lived twelve months. There had been no miscarriage. Nenstruation commenced at the age of thirteen, had always been regular, not very free in amount, and without pain. The patient had been quite well both before and since her confinement, and had menstruated regularly till the last week in August, 1891. She saw a little at the end of November, 1891, and again in December, 1891, about the time of her ordinary monthly periods; the flow was scanty, but there was no pain, except with the loss in November. On Nov. 24th, 1891, she commenced to vomit and was sick for two days. During this time she says that she had pain right across her stomach. She took to her bed and sent for Mr. Archer Wood of Dulwich. Mr. Wood found her markedly anæmic and very much prostrated. On examining the abdomen he found a hard, rounded lump rising above the right Poupart's ligament and apparently springing from out of the true pelvis. The patient complained of a few "pleuritic pains," but these ceased after a few days and improvement took place. A similar attack occurred a week later, and a third after another fortnight's interval, but these two were not so severe as the first attack. After these attacks there was no return of pain, but as the lump did not disappear the patient was not allowed to leave her bed. The lump was first noticed on the right side three days after the first attack of pain. On Dec. 15th Mr. Archer Wood asked me to see the patient in consultation. On this date she was feeling well, free from pain, and anxious to be allowed to leave her bed. 'There was a slight degree of anæmia. The breasts were suggestive of pregnancy. The abdomen was full, and above the right Poupart's ligarnent there was a tumour with a rounded top, firm and solid to palpation. fixed in position, very little tencler to the touch, and reaching half-way up to the level of the umbilicus. By vaginal examination the uterus was found pusher over to the left of the middle line and fixed; while to the right and behind there was a firm mass which depressed the vaginal roof on that side and was evidentily continuous with the abdominal tumour. The diagnosis pointed clearly to an extra-uterine pregnancy on the right side, and the symptoms suggested the occurrence of rupture with a moderate out-pouring of blood. As the patient was so well it was decided to leave matters alone and watch the furthor progress of events, the patient meanwhile remaining absolutely in bed. About the middle of January, 1892, Mr. Archer Wood wrote to tell me that all was going on favourably, and that there had not been any further sign of bleeding, but he thought that the tumour was increasing in size. Under these conditions we decided to move the patient into St. Mary's Hospital, so that I might have her under close observation and be able to operate at once if need arose. On Feb. 3rd the patient was admitted to St. Mary's Hospital, and the following notes were taken. On inspection of the abdomen there was found a dome-shaped swelling in the right iliac region which reached above the umbilicus to the height of two inches. The skin was freely movable over the tumour and there was complete dulness on percussion. No movements or adventitious sounds could be detected. The following were the measurements : right anterior superior iliac spine to umbilicus, $5 \frac{1}{4}$ in.; left ditto, $5 \frac{1}{2}$ in.; umbilicus to xiphoid cartilage, $5 \frac{3}{4}$ in.; umbilicus to symphysis pubis, $6 \frac{1}{2}$ in.; left side (horizontal), spinal column to umbilicus, $12 \frac{1}{2}$ in.; right side, ditto, $13 \frac{3}{4}$ in. (over the most prominent part of the tamour). On vaginal examination the body of the uterus was felt pushed over to the left side; the cervix pointed backwards and to the right. The body of the uterus was considerably enlarged, and the right fornix of the vagina was occupied by a hard swelling which seemed to be continuous with the abdominal tumour. The swelling in the right iliac region was not obviously distinct from the uterus. On Feb. 11th the patient said she had had no pain since admission. No movements had been felt, and no sounds had been heard over the tumour. On Feb. 19th the circumference of the body measured over the most prominent part of the tumour $30 \mathrm{in}$. The following were the measurements: left anterior superior spine to umbilicus, $6 \frac{1}{2}$ in. ; right ditto, $5 \frac{1}{2}$ in. ; umbilicus to xiphoid cartilage, $6 \frac{1}{2}$ in.; umbilicus to symphysis pubis, $6 \frac{3}{4}$ in. On the night of the 18 th, about 12 o'clock, the patient was awakened by a sharp pain in her right side, which passed from behind forwards through the tumour. She went to sleep in an hour's time, but the pain awakened her at interval for three or four hours. She did not feel at all sick and felt quite well again in the morning. On Feb. 23rd there was no return of pain. On the anterior abdominal wall on the left side, half-way between the anterior superior iliac spine and the umbilicus, fcetal movements were distinctly felt. On March 10th the measurement round the abdomen was $31 \frac{1}{2}$ in. On March 28th the patient said she felt morements every day, but had no pain. The tumour was steadily enlarging upwards and to the right. The urine was acid, contained no albumin, and the specific gravity was 1026. It deposited urates. The ineasurement around the abdomen equalled 32 $\frac{1}{4}$ in. On April 12th the patient was progressing favourably. The girth now equalled $33 \frac{1}{2}$ in. So far no shreds of membrane or decidual cast had been expelled. As by the end of this month the patient would have reached about the 250th day of gestation, it had been decided to operate at that time and not go quite up to full term. On $A$ pril 27 th the abdomen of the patient closely resembled the appearance of an ordinary case of gravidity about the end of the eighth month, except that there was a marked bossing on the right side between the lower ribs and Poupart's ligament. Careful palpation led to the belief that the swelling was caused by the placenta, a view which was found to be correct at the operation. By combined abdominal and vaginal examination the child was felt to be lying obliquely to the vertical axis of the abdomen; the head resting on the brim of the pelvis towards the left side, the back of the fotus directed forwards, and the breech high up to the right of the middle line. On percussion dulness was found nearly up to the xiphoid cartilage, extending outwards into the right flank, but good resonance was obtained on the left side of the abdomen. Rising about three inches above the level of the symphysis pubis there 